\title{
Tracheal resection in an infant with double aortic arch and associated
}

\section{tracheomalacia}

\author{
JH DARK, B SETHIA, JCS POLLOCK \\ From the Department of Cardiac Surgery, Royal Hospital for Sick Children, Glasgow
}

Until recently the outlook for neonates with distal tracheal stenosis was uniformly poor, but several reports ${ }^{1-4}$ have suggested that tracheal resection may be performed successfully in infants with this condition. We report the case of an infant who underwent surgery for double aortic arch and subsequently required resection of the distal trachea because of localised tracheomalacia. In contrast to previous reported cases, tracheal resection was facilitated by the use of cardiopulmonary bypass.

\section{Case report}

A full term male infant weighing $2.88 \mathrm{~kg}$ developed tachypnoea soon after birth and over the next week developed stridor and difficulty with feeding. A chest radiograph at that time showed collapse of the right lower lobe and a barium swallow demonstrated posterior indentation of the oesophagus. The infant was referred to our hospital for further investigation.

At angiography the presence of a double aortic arch was confirmed. The larger arch was on the right side and passed behind the oesophagus. There was also a high ventricular septal defect. At operation, performed through a left thoracotomy 14 days after birth, the anterior aortic arch was divided without difficulty.

The infant was extubated on the first postoperative day but soon developed severe stridor, which was thought to be secondary to an area of tracheomalacia. In the next two weeks two further unsuccessful attempts were made to extubate the infant and a tracheogram (fig 1) showed a discrete area of tracheal collapse $1 \mathrm{~cm}$ long, just proximal to the carina. A further attempt to extubate the baby one week later was also unsuccessful. Throughout this time the position of the endotracheal tube was critical. Airway obstruction occurred whenever the end of the tube retracted above the area of tracheal collapse. We therefore decided to resect the distal trachea.

At a second operation, performed through a median sternotomy when the child was 34 days old, the area of tracheal collapse was found to correspond to the level of the original vascular ring. The infant was placed on cardiopulmonary bypass and a $1 \mathrm{~cm}$ tracheal segment was resected without difficulty. The trachea was reanastomosed with interrupted sutures of monofilament polyglycolic acid (Dexon). Histological examination of the resected speci-

Address for reprint requests: Mr B Sethia FRCS, Royal Infirmary, Glasgow G31 2ER.

Accepted 5 May 1983

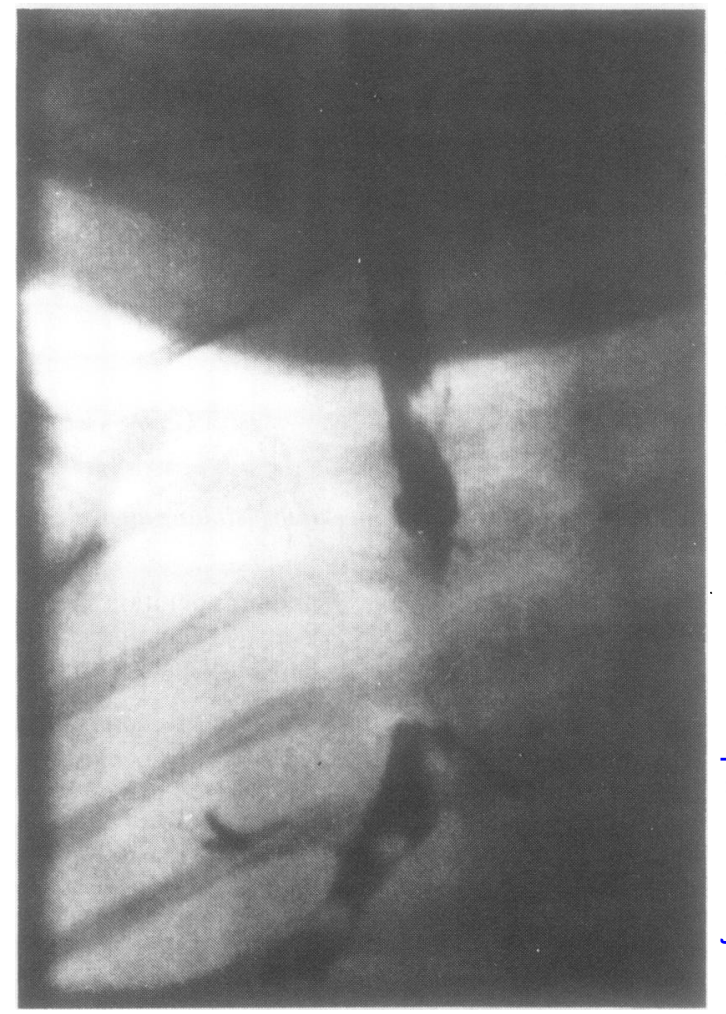

Fig 1 Tracheogram showing the area of tracheal collapse proximal to the carina.

men showed widespread mucosal ulceration and diminished fibroelastic tissue.

After a further four weeks of elective intubation the child was extubated. His postoperative progress was delayed by intermittent collapse of the left lung, which was thought to be due to a paretic left hemidiaphragm. He $\underset{\gamma}{ }$ recovered from this over the next two months and the 0 infant was discharged home. Six months later the child is developing normally and he has not had any further $\stackrel{\mathcal{S}}{?}$ respiratory problems. He still has the ventricular septal defect.

A penetrated chest radiograph taken when he was 6 months old shows a normal lumen at the site of tracheal anastomosis (fig 2). 


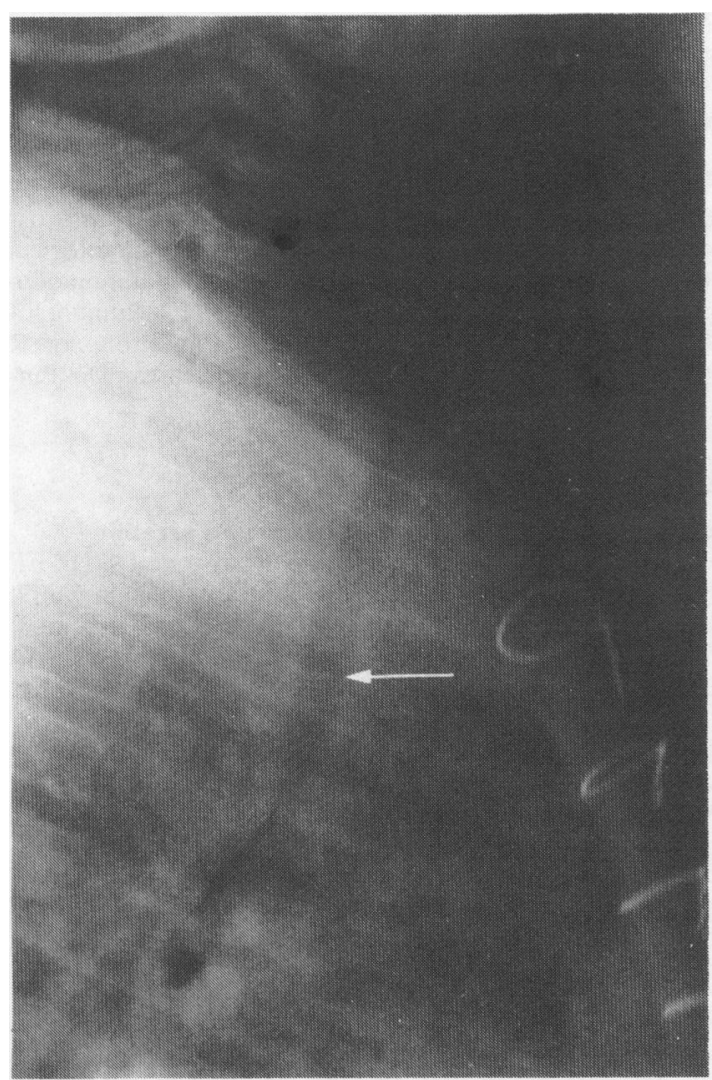

Fig 2 Penetrated chest radiograph at the age of 6 months, showing no evidence of residual tracheal stenosis (arrow marks site of anastomosis).

\section{Discussion}

Surgical treatment of distal tracheal lesions in infancy is hazardous. ${ }^{56}$ Palliation of congenital distal tracheal stenosis followed by elective tracheal resection at the age of six months was attempted by Nelson $e t \mathrm{al}^{5}$ but the baby died one month later. More recently, there have been four accounts ${ }^{1-4}$ of successful distal tracheal resection in infants. Surgery was undertaken at the age of four and five months in two of these cases. ${ }^{34}$ In the other two cases the age of the infant at operation is not stated.

In all these reports the tracheal anastomosis was performed around endobronchial tubes ventilating one ${ }^{2}$ or both $^{134}$ distal bronchi. In one case ${ }^{4}$ resection of the tracheal stenosis with reconstruction of the carina and right main bronchus was performed. A similar technique, described and advocated by Grillo, ${ }^{7}$ is the method of choice for tracheal resection in adults. In a series of $\mathbf{3 5}$ carinal resections in adults with carcinoma of the lung ${ }^{8}$ cardiopulmonary bypass was used only once. In this case reconstruction of the posterior wall of the main pulmonary artery was required.

In our case, after division of the anterior aortic arch exposure of the carina was straightforward and fixation of the innominate and right carotid arteries to the posterior surface of the sternum ${ }^{6}$ was unnecessary. Through the use of cardiopulmonary bypass we were able to perform an accurate tracheal anastomosis in a $3.5 \mathrm{~kg}$ infant without the risks inherent in selective bronchial intubation.

The diagnosis of tracheal collapse or stenosis is best established by a tracheogram. Bronchoscopy in small infants is hazardous ${ }^{9}$ and may fail to identify the extent of the lesion. Tracheostomy should be avoided as it reduces the available length of trachea at the time of tracheal resection.

Experimental work in puppies has shown that tracheal growth is adequate after resection of a short segment of trachea. ${ }^{10}$ This was confirmed in our case by the very satisfactory clinical progress and the adequate tracheal lumen seen on the penetrated chest radiograph six months after surgery.

We suggest that cardiopulmonary bypass may be a useful technique when a distal tracheal segment is resected in an infant as it facilitates the meticulous construction of the tracheal anastomosis that is essential to success.

\section{References}

' Mansfield PB. Tracheal resection in infancy. $J$ Pediatr Surg 1980;15:79-81.

${ }^{2}$ Harrison MR, Heldt GP, Branch RC, de Lorimier AA, Gregory AA. Resection of distal tracheal stenosis in a baby with agenesis of the lung. $J$ Pediatr Surg 1980;15:938-43.

${ }^{3}$ Mattingly WT, Belin RP, Todd EP. Surgical repair of congenital tracheal stenosis in an infant. J Thorac Cardiovasc Surg 1981;81:738-40.

4 Weber TR, Eigen H, Scott PH, Krishna G, Grosfeld JL. Resection of congenital tracheal stenosis involving the carina. $J$ Thorac Cardiovasc Surg 1982;84:200-3.

${ }^{5}$ Nelson CS, McMillan IKR, Bharucha PK. Tracheal stenosis, pulmonary agenesis and patent ductus arteriosus. Thorax 1967;22:7-12.

${ }^{6}$ Harrison MR, Hendren WH. Agenesis of the lung complicated by vascular compression and bronchomalacia. J Paediatr Surg 1975;10:813-7.

${ }^{7}$ Grillo HC. Tracheal surgery. In: Keen G, ed. Operative surgery and management. Bristol: John Wright \& Sons, 1981:651-60.

${ }^{8}$ Grillo HC. Carcinoma of the lung: what can be done if the carina is involved? Am J Surg 1982;143:694-6.

' Jarick JS, Kirikati SN, Yacoub U, Groff DB. Congenital funnelshaped tracheal stenosis. J Thorac Cardiovasc Surg 1982;83:761-6.

${ }^{10}$ Maeda M, Grillo HC. Tracheal growth following anastomosis in puppies. J Thorac Cardiovasc Surg 1972;64:304-13. 